\title{
Improved Tire Efficiency through Elastomeric Polymers Enhanced with Carbon-Based Nanostructured Materials
}

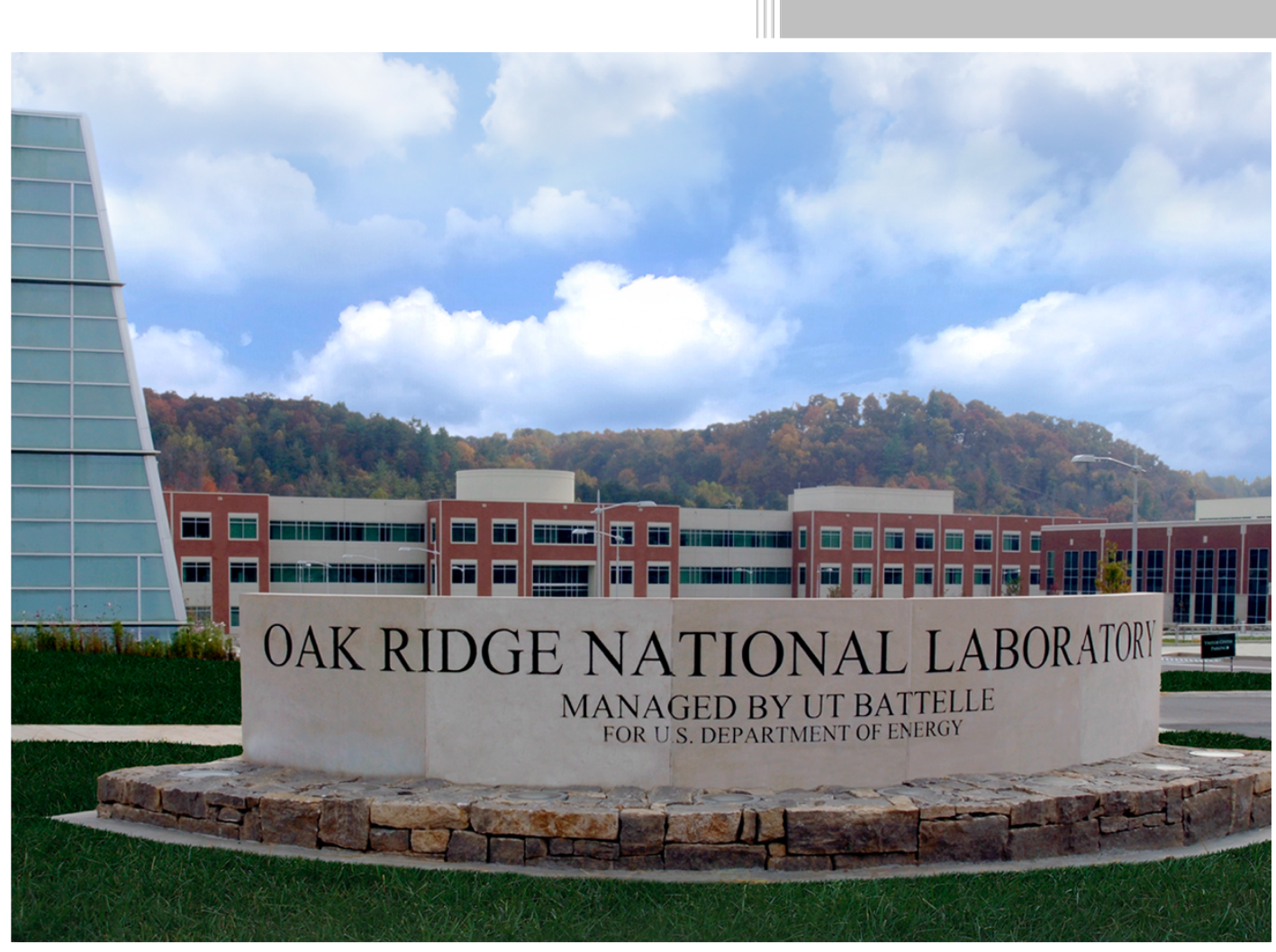

\section{Approved for public release. Distribution is unlimited.}

Georgios Polyzos, ORNL Jaehyeung Park, ORNL Jaswinder Sharma, ORNL

November 16, 2018 


\section{DOCUMENT AVAILABILITY}

Reports produced after January 1, 1996, are generally available free via US Department of Energy (DOE) SciTech Connect.

Website http://www.osti.gov/scitech/

Reports produced before January 1, 1996, may be purchased by members of the public from the following source:

National Technical Information Service

5285 Port Royal Road

Springfield, VA 22161

Telephone 703-605-6000 (1-800-553-6847)

TDD 703-487-4639

Fax 703-605-6900

E-mail info@ntis.gov

Website http://www.ntis.gov/help/ordermethods.aspx

Reports are available to DOE employees, DOE contractors, Energy Technology Data Exchange representatives, and International Nuclear Information System representatives from the following source:

Office of Scientific and Technical Information

PO Box 62

Oak Ridge, TN 37831

Telephone 865-576-8401

Fax 865-576-5728

E-mail reports@osti.gov

Website http://www.osti.gov/contact.html

This report was prepared as an account of work sponsored by an agency of the United States Government. Neither the United States Government nor any agency thereof, nor any of their employees, makes any warranty, express or implied, or assumes any legal liability or responsibility for the accuracy, completeness, or usefulness of any information, apparatus, product, or process disclosed, or represents that its use would not infringe privately owned rights. Reference herein to any specific commercial product, process, or service by trade name, trademark, manufacturer, or otherwise, does not necessarily constitute or imply its endorsement, recommendation, or favoring by the United States Government or any agency thereof. The views and opinions of authors expressed herein do not necessarily state or reflect those of the United States Government or any agency thereof. 
Energy and Transportation Science Division

\title{
IMPROVED TIRE EFFICIENCY THROUGH ELASTOMERIC POLYMERS ENHANCED WITH CARBON-BASED NANOSTRUCTURED MATERIALS
}

\author{
Georgios Polyzos, ORNL \\ Jaehyeung Park, ORNL \\ Jaswinder Sharma, ORNL
}

Date Published: November 2018

\author{
Prepared by \\ OAK RIDGE NATIONAL LABORATORY \\ Oak Ridge, Tennessee 37831-6283 \\ managed by \\ UT-BATTELLE, LLC \\ for the \\ US DEPARTMENT OF ENERGY \\ under contract DE-AC05-00OR22725
}

Approved for Public Release 


\begin{abstract}
In materials science of elastomers the influence of manufactured nanomaterial filler particles is of utmost significance for the performance of innovative rubber products, i.e., passenger and commercial tires with ultralow rolling resistance but high traction. Advances in both performance areas are imperative for the development of improved tire efficiency to meet DOE's fuel consumption reduction target of 4\%, all while maintaining or improving wear characteristics of the tire. Recent research efforts focus mainly on the development of composite tires based on carbon black and silica. The project goal was to replace existing fillers (such as carbon black and silica) with higher performance materials (viz., graphene and silica nanofibers). The proposed approach capitalized on the recent advances in nanomaterial and graphene synthesis and functionalization by our group and suggests a promising avenue for the amalgamation of cutting-edge nanotechnologies that can be utilized toward DOE's technical targets.
\end{abstract}

\title{
Benefits to the Funding DOE Office's Mission
}

In the United States road vehicles account for more than $80 \%$ of motorized transportation and are considered to be the driving force for the steep growth in oil demand [1]. Several studies have indicated the importance of the tire rolling resistance for significant reductions in fuel consumption. The rolling resistance can be responsible for up to $25 \%$ of the energy required to drive at highway speeds [2] and a $10 \%$ reduction in tire rolling resistance yields fuel savings $1-2 \%[1,3]$. The above-referred results are in excellent agreement with the research conducted for the California Energy Commission, which concluded that approximately 1.5 to $4.5 \%$ fuel consumption could be saved by using low resistance tires [4]. In response to Vehicle Technologies funding opportunity announcement we developed innovative nanocomposite materials that will reduce the fuel consumption by reducing the tire rolling resistance. The targeted fuel consumption reduction was $4 \%$, while maintaining traction and wear resistance.

\section{Statement of Objectives}

The objective of the project was to reduce the hysteretic losses of elastomers that are used for manufacturing vehicle tires. Composite elastomers based on graphene and silica nanofibers were developed. The filler material should not compromise the wear and tear resistance of the tire. The specific objectives of the project are:

- Reduce the rolling resistance of the tire.

- Replace existing fillers (such as carbon black and silica) with higher performance materials.

- Tailor the viscoelastic properties of the composite elastomer.

- Design of new materials with tailored and complementary properties that will provide parallel improvements.

- Improve tire efficiency and meet DOE's fuel consumption reduction target of 4\%.

- Scale up the synthesized filler material.

- Test the properties of the composite elastomers.

- Enable fabrication techniques that can be scaled in manufacturing environment.

\section{Technical Discussion}

Graphene nanoplatelets (GnPs) and silica nanofibers ( $\mathrm{SnFs}$ ) were synthesized using techniques that can be scaled. The GnPs were exfoliated and functionalized with organic groups in order to be compatible with the SnFs and the styrene-butadiene-rubber (SBR) elastomer. Composite elastomers were fabricated at several filler weight contents. The mixing procedure was tailored in order to achieve good dispersion of the fillers in the elastomer. The properties of the composite elastomers were found to depend on the dispersion of the filler material. The chemical functionality of the fillers and the mixing procedures were optimized to achieve good dispersion of the fillers in the SBR.

Graphene nanoplatelets (GnPs) were functionalized using several organic groups. The group functionalities and the synthesis conditions were optimized in order to achieve good dispersion of the 
GnPs in the styrene-butadiene-rubber (SBR) elastomer. A scalable method for the synthesis of silica nanofibers (SnFs) was developed. The diameter of the fibers is smaller than $100 \mathrm{~nm}$. The properties of the fibers were evaluated using scanning electron microscopy (SEM) atomic force microscopy (AFM) techniques. Composite elastomers based on SBR, GnPs, and SnFs were synthesized at several weight contents of the filler material. To achieve $4 \%$ fuel saving without compromising the tire performance the $\mathrm{SnF}$ and $\mathrm{GnP}$ contents were defined. By tuning the functionality and dispersion of the fillers we were able to reduce the hysteretic losses and at the same time to enhance the mechanical properties (Modulus) of the tire elastomer. The filler materials are described below:

\section{Functionalized GnPs}

Organically modified GnPs were synthesized in a solution. The mixture was refluxed while stirring and then filtrated with a porous membrane with an average pore size of $0.2 \mu \mathrm{m}$. The filtrated powder was rinsed with ethanol for three times to remove the non-reacted organic groups that were physically absorbed on the graphene surface. The powder was dried in an oven at $80{ }^{\circ} \mathrm{C}$ for $24 \mathrm{~h}$. Schematic images of the modified GnPs are shown in Figure 1. The d-spacing between the graphene platelets increased from 8.4 to $13.5 \AA$ due to the intercalated organic groups. The intercalated groups were found to promote the exfoliation of the GnPs in the SBR.

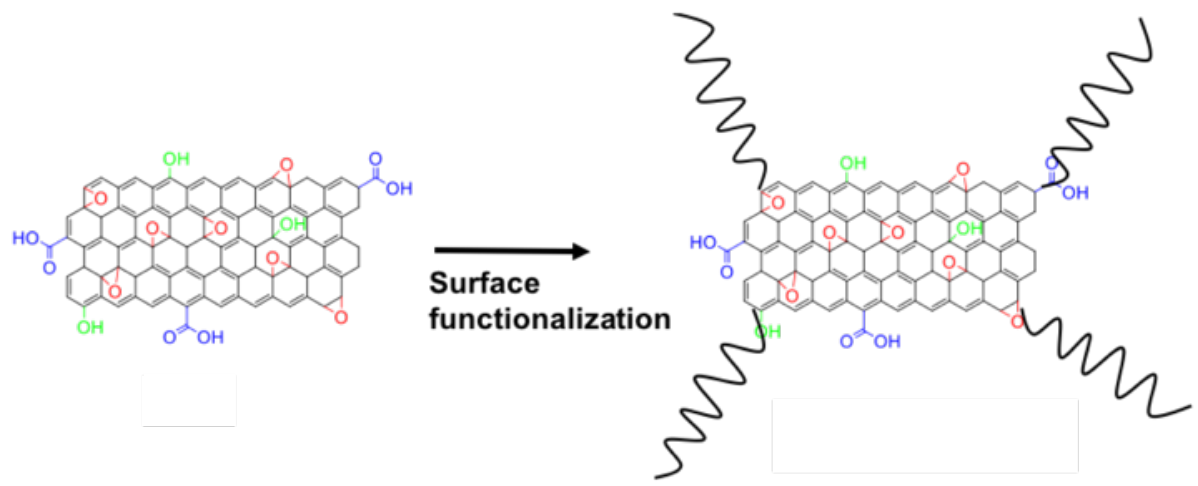

Figure 1. Schematic images of organically modified graphene nanoplatelets (GnPs)

\section{Synthesis of SnFs}

A scalable method for the synthesis of silica nanofibers SnFs was developed. The nanofibers were fabricated using an electrospining technique with sol-gel precursors. A schematic representation of the synthesis method is shown in Figure 2. The diameter of the fibers is smaller than $100 \mathrm{~nm}$ according to the scanning electron microscopy (SEM) images shown in Figure 3. The average size is approximately 60 $\mathrm{nm}$. Nitrogen adsorption and desorption measurements were performed to calculate the surface area of the SnFs. The measured surface area is $670 \mathrm{~m}^{2} / \mathrm{g}$. 


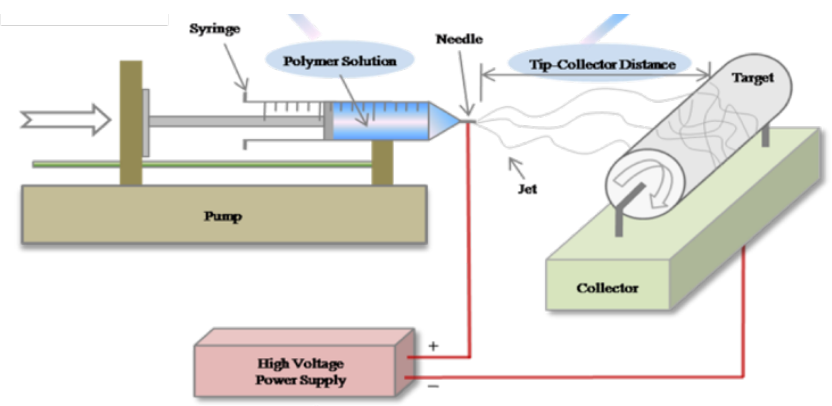

Figure 2. Experimental setup for the synthesis of SnFs.
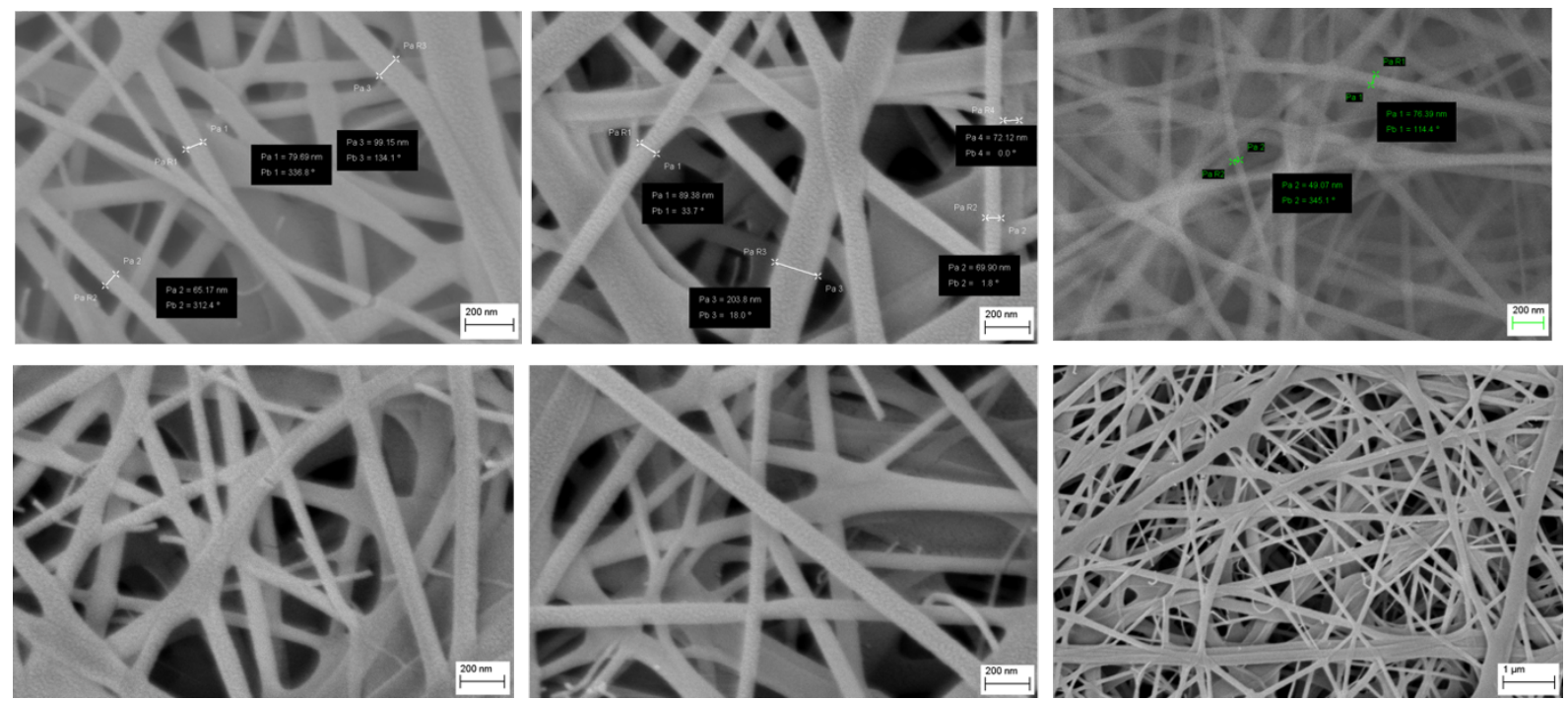

Figure 3. SEM images of synthesized silica fibers using the experimental setup in Figure 2. The diameter of the fibers is smaller than $100 \mathrm{~nm}$.

\section{Mechanical properties of the SBR composites}

The mechanical properties of the SBR composites were measured using dynamic mechanical analysis (DMA) techniques. The tand value for the commercial tire elastomer is 0.46 at $23{ }^{\circ} \mathrm{C}$. In order to achieve the $4 \%$ fuel reduction, the tand value must decrease to 0.3 . DMA measurements were performed to calculate the hysteretic losses (tand values). The DMA results of the composites are shown in Figure 4. The tand of the developed non-crosslinked composite is approximately 0.13 , which is adequate to achieve the targeted $4 \%$ fuel reduction. The crosslinking density of the composite elastomer must be optimized to further enhance the storage Modulus values. 

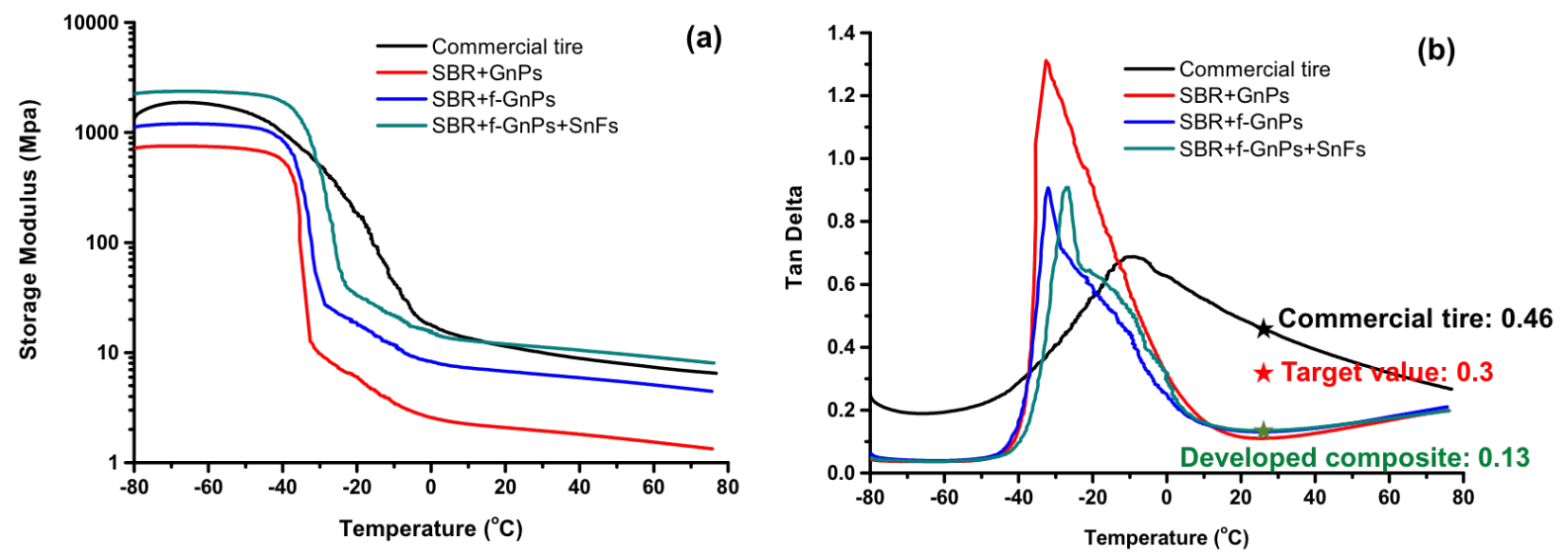

Figure 4. (a) Modulus values of the synthesized composites at a broad temperature range. (b) Tand values of the synthesized composites at a broad temperature range. The respective values of a commercial elastomer that was provided by our industrial partner are also included.

The dispersion of the fillers in the elastomer matrix was evaluated using transmission electron microscopy (TEM) and SEM techniques. The TEM images of the unfilled SBR, SBR filled with GnPs, and SBR filled with functionalized GnPs, are shown in Figure 5. The agglomerated structures are more pronounced when the GnPs are not functionalized (Figure 5b). The introduced organic groups on the surface of the graphene promoted the dispersion of the fillers in the elastomer (Figure 5c).
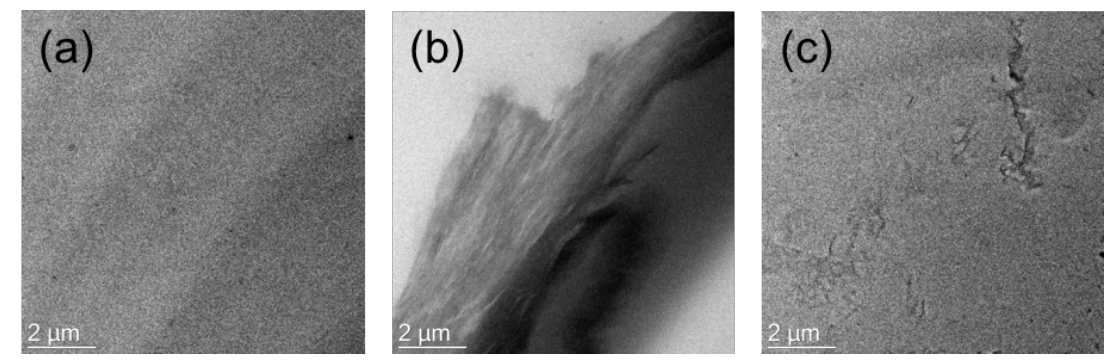

Figure 5. TEM images of the (a) unfilled SBR, (b) SBR filled with GnPs (c) SBR filled with functionalized GnPs.

SEM images of the composites filled with SnFs and GnPs composites are shown in Figure 6. When the $\mathrm{GnPs}$ are not functionalized, the GnP fillers aggregate (Figure 6b). The functionalized GnPs and SnFs are compatible with the SBR matrix and result in a better dispersion of the fillers (Figure $6 \mathrm{c}$ ). 

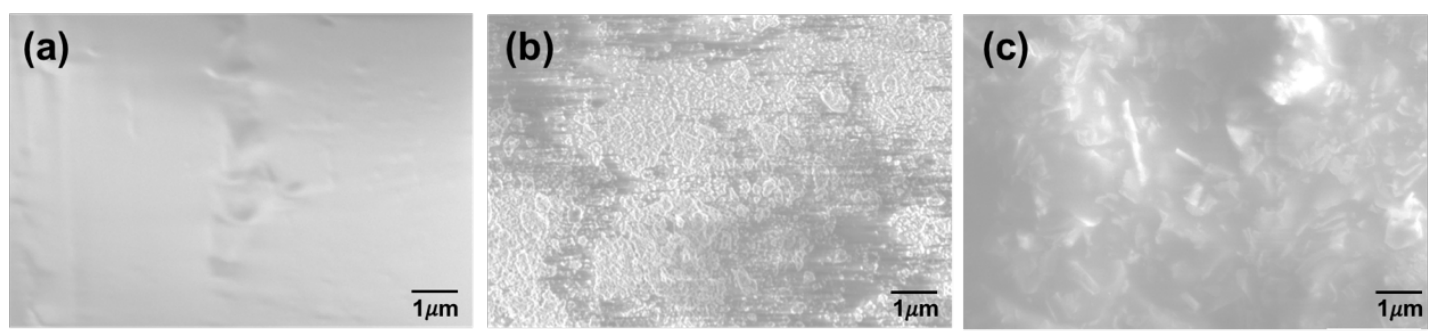

Figure 6. SEM images of the (a) unfilled SBR, (b) SBR filled with GnPs (c) SBR filled with functionalized $\mathrm{GnPs}$ and $\mathrm{SnFs}$

Graphene oxide (GO) nanoplatelets were functionalized with organic coupling agents based on sulfur (S) and methyl groups. The chemical composition of the fillers was investigated. The nanoplatelets were exfoliated in styrene-butadiene-rubber (SBR) and styrene-butadiene-styrene (SBS) elastomers. Composite elastomers were fabricated at several filler weight contents. Mixing procedures were developed in order to achieve good dispersion of the filler material in the elastomers. We collaborated with a major tire manufacturer. The mechanical and abrasion resistance properties of the synthesized elastomers were studied. To improve the vulcanization of the composite tire elastomers, we introduced sulfur (S) groups on the GO nanoplatelets by chemically attaching organic coupling agents based on sulfur. The filler material was successfully reduced with hydrazine. The reduction was performed to decrease the oxygen content of the surface of the fillers and enhance their mechanical performance. After the hydrazine reduction, the filler material was washed with distilled water and dried in a vacuum oven. X-ray photoelectron spectroscopy (XPS) and X-ray diffraction (XRD) techniques were used to characterize the surface chemistry of the prepared fillers. XPS was used to study the covalent bond formation between the organic coupling agents and the GO. The results are summarized in Figures 7, 8, and 9. In brief, the C1s XPS spectra in Figures 7 and 8 clearly indicate that the oxygen content of the rGO fillers decreases after the reduction process (the peak intensity at $287 \mathrm{eV}$, which is assigned to the $\mathrm{C}-\mathrm{O}$ bonds decreased in the $\mathrm{rGO}$ sample). In Figure 9, the peak around $400 \mathrm{eV}$, in the N1s high resolution XPS spectrum, is attributed to the amide bond formation between GO and the coupling agent. The coupling agent was successfully covalently bonded to the GO surface.

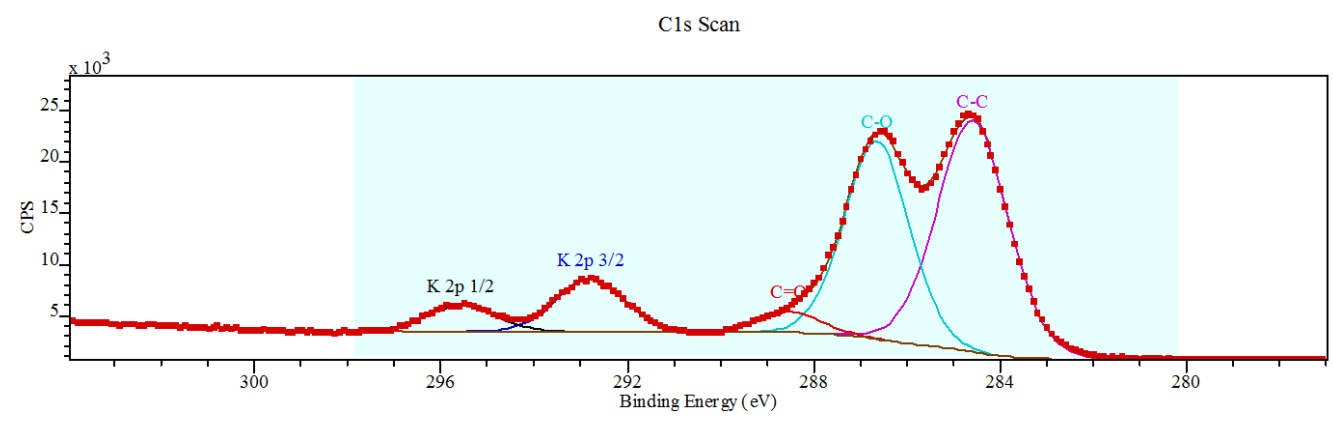

Figure 7. High resolution C1s XPS analysis of the functionalized GO fillers before the reduction. 


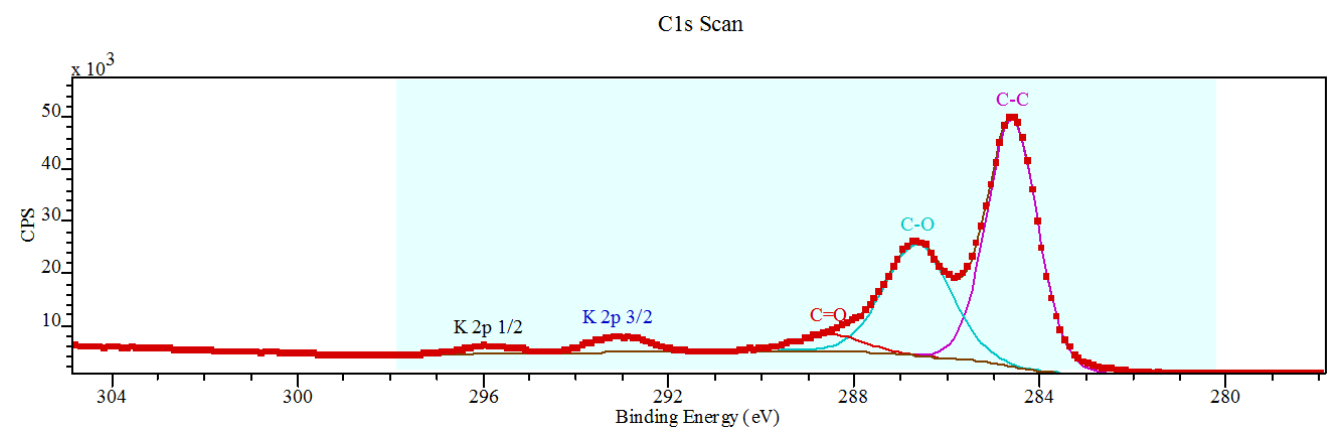

Figure 8. High resolution C1s XPS analysis of the functionalized GO fillers after the reduction.

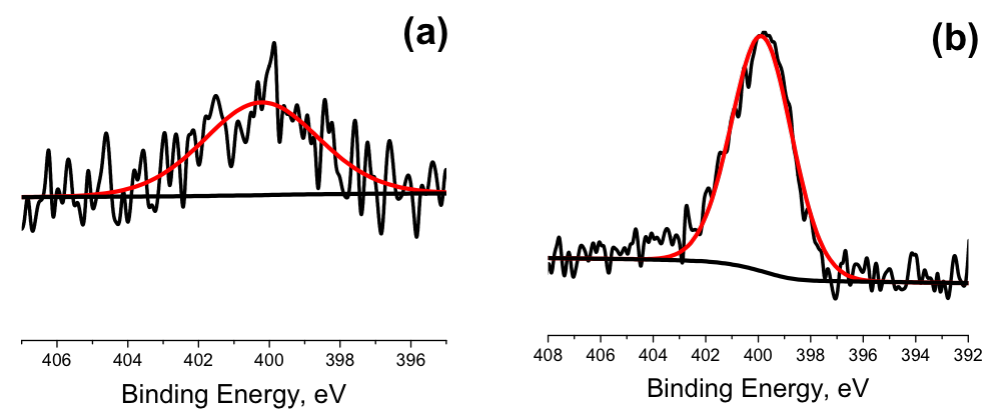

Figure 9. High resolution N1s XPS analysis of the functionalized GO fillers (a) before and (b) after the reduction.

The GO fillers were dispersed in SBS elastomer. The mixing was performed in solvent and ultrasonic agitation was applied to assist the filler dispersion. Nano-indentation measurements were performed on 100 different areas in each sample. The Modulus values were calculated from the maximum load versus displacement plots. The maximum Modulus improvement was approximately one order of magnitude. Similar values were obtained from the tensile (Instron) measurements.

The wear resistance of composite SBS-GO elastomers was evaluated using a Taber 5135 rotary platform abrasion tester. Abrasive wear experiments were performed on samples turning against two abrading CS10 wheels at $60 \mathrm{rpm}$. The samples were subjected to 100 consecutive abrading cycles. Scanning electron microscopy (SEM) and atomic force microscopy techniques were used to characterize the abraded surface of the unfilled SBS and SBS-GO samples. SEM images of the abraded SBS and SBS-GO surface are shown in Figure 10. The unfilled SBS surface was abraded significantly. SBS fragments were detached from the surface and are aggregated on the surface of the sample. The abrasion of the SBS-GO was minimal. The surface indentations are shallow (a few micrometers in depth). The graphene fillers improved the wear resistance of the composite elastomer. This can be attributed to the strong interactions between the polymer elastomer matrix and the filler material. 

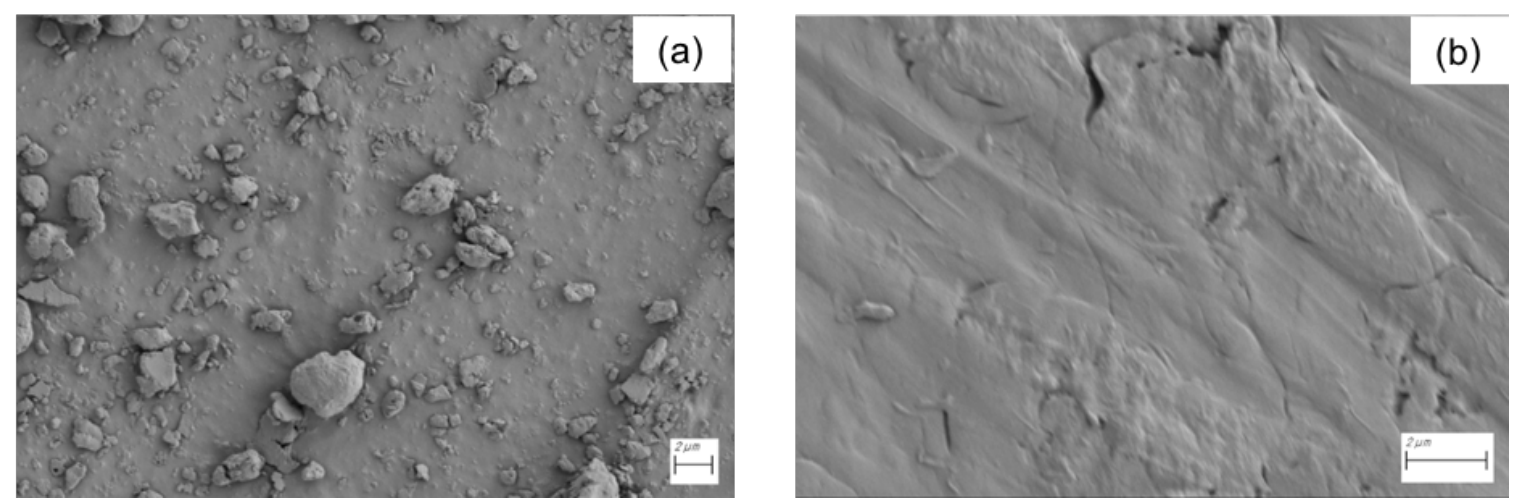

Figure 10. SEM images of the abraded surface of (a) unfilled SBS and (b) SBS-GO samples after 100 abrading cycles.

\section{Subject Inventions}

US Patent Application entitled "Nanocomposite Additives Based on Graphene Sheets and Silica Nanofibers" Serial No. 16/000,975, Filed: June 6, 2018

\section{Commercialization Possibilities}

The developed elastomers can benefit the automotive industry and applications associated with the manufacturing of nanocomposite elastomers.

\section{Conclusions}

- GnPs were successfully functionalized and showed good dispersion in the polymer elastomer when mixed in solution.

- Electrospun SnFs were synthesized with diameter smaller than $100 \mathrm{~nm}$. The average diameter was $60 \mathrm{~nm}$. The surface area was $670 \mathrm{~m}^{2} / \mathrm{g}$.

- The combination of $\mathrm{SnF}$ and functionalized GnP fillers synergistically improved the mechanical performance of the elastomer.

- The weight content of the filler material was optimized.

- Elastomers filled with GnPs and SnFs were synthesized.

- It is feasible to achieve $4 \%$ reduction in the fuel efficiency and at the same time to enhance the mechanical performance of the tire. The target tand value is 0.3 . The non-crosslinked composites were found to exhibit tand value 0.13 and at the same time to improve up to $20 \%$ the mechanical properties of the elastomer.

- Sulfur (S) groups were chemically bonded on the surface of graphene oxide (GO) filler material.

- The functionalized GO nanoplatelets were successfully reduced (rGO).

- Mixing techniques were developed to synthesize composite elastomers.

- Nano-indentation measurements were performed on composite elastomers.

- A 10-fold increase in the Modulus values was achieved for certain graphene composite elastomers.

- Abrasion testing was performed on the elastomers.

- The graphene fillers improved the wear resistance of the composite elastomer according to Taber abrasion testing.

\section{References}


1. J.A. Carpenter Jr., J. Gibbs, A.A. Pesaran, L.D. Marlina, K. Kelly, "Road transportation vehicles" MRS Bulletin 33, 439-444, 2008.

2. B.E. Lindemuth, "An overview of tire technology", Chapter 1 in "The pneumatic tire", U.S. Department of Transportation, National Highway Traffic Safety Administration, February 2006.

3. T. Markel, A. Brooker, V. Johnson, K. Kelly, M. O'Keefe, S. Sprik, K. Wipke, "ADVISOR: a systems analysis tool for advanced vehicle modeling" J. Power Sources 110, 255-266, 2002.

4. California Energy Commission, Fuel-Efficient Tires and CEC Proceeding Documents Page, www.energy.ca.gov/transportation/tire_efficiency/documents/index.html (accessed January 2008).

$\begin{array}{ll}\text { Acronyms } & \\ \text { GnPs } & \text { graphene nanoplatelets } \\ \text { f-GnPs } & \text { functionalized graphene nanoplatelets } \\ \text { SnFs } & \text { silica nanofibers } \\ \text { SBR } & \text { styrene-butadiene-rubber } \\ \text { SBS } & \text { styrene-butadiene-styrene } \\ \text { SDS } & \text { safety data sheet } \\ \text { S } & \text { sulfur } \\ \text { DMA } & \text { dynamic mechanical analysis } \\ \text { SEM } & \text { scanning electron microscopy } \\ \text { TEM } & \text { transmission electron microscopy } \\ \text { AFM } & \text { atomic force microscopy } \\ \text { GO } & \text { graphene oxide } \\ \text { rGO } & \text { reduced graphene oxide } \\ \text { XPS } & \text { x-ray photoelectron spectroscopy } \\ \text { XRD } & \text { x-ray diffraction }\end{array}$

